\title{
No drought about it: effects of supplemental hydration on the ecology, behavior, and physiology of free-ranging rattlesnakes
}

\author{
Griffin D. Capeharta, Camilo Escallón ${ }^{\mathrm{b}}$, Ben Vernasco ${ }^{\mathrm{b}}$, Ignacio T. Moore ${ }^{\mathrm{b}}$, Emily N. Taylora, ${ }^{\mathrm{*}}$ \\ a Department of Biological Sciences, California Polytechnic State University, San Luis Obispo, CA 93407- \\ 0401, USA \\ bepartment of Biological Science, Virginia Tech, Blacksburg, VA 24061, USA \\ *corresponding author. Email address: etaylor@calpoly.edu
}

\begin{abstract}
Hydration is a critical element for many physiological processes in vertebrates. While it seems intuitive that drought is stressful to animals, studies examining drought are typically observational and do not explicitly assess how the hydration state of study subjects influences their physiology and behavior. We examined how hydration affects several physiological and behavioral variables in free-ranging Northern Pacific rattlesnakes (Crotalus oreganus oreganus) by experimentally manipulating their hydration levels in the field. Our results suggest that supplemental water has a significant effect on reproduction, as all hydrated females gave birth during the experiment, while no control females did. We saw no effect of hydration on movement parameters; males moved a larger total distance and had larger home ranges than females, regardless of hydration status. Interestingly, body condition at the end of the study was significantly higher in hydrated snakes, suggesting that hydrated individuals might have been acquiring more food than control snakes. We saw no effect on baseline stress hormone concentrations or their increase in response to an acute stressor. Additional experimental studies are needed to better understand the pivotal roles of hydration in the physiology and behavior of reptiles.
\end{abstract}

Keywords: Hydration, physiology, rattlesnake, reproduction, body condition 


\section{INTRODUCTION}

Hydration is a crucial component of the overall homeostatic balance an organism must maintain for survival. As such, the ability of an animal to acquire and use water efficiently is subject to strong selection in nature, especially in dry climates. Emphasizing the importance of an animal's water conservation strategies, scientists have documented a recent increase in drought severity in arid regions and predict this trend to continue (Trenberth et al., 2014). Prolonged drought may have serious impacts on animals in many different habitats, including arid areas where animals are often already highly water-stressed. Seasonal or annual variation in water availability can impact animals in diverse ways, including changes in behavior, feeding rates, and reproduction. Many studies on the relationship between hydration and these parameters have used reptiles as model organisms due to their myriad of adaptations to withstand long periods with little water (reviewed in Shoemaker and Nagy, 1977), as well as the ease with which individuals can be captured and studied in the wild. Prominent examples include reduction in activity during dry conditions in chuckwallas (Nagy, 1972), increased metabolic rate in desert tortoises in high rainfall years (Henen et al., 1998), reduced survival during drought years in water snakes (Winne et al. 2010), reliance of sea snakes on fresh water (Lillywhite et al., 2008), and strong effects of rainfall patterns on movement and reproduction in desert tortoises (Duda et al., 1999; Henen, 2002; Turner et al., 1986). Because studies that experimentally manipulate hydration typically take place in laboratory settings (e.g., Churchill and Storey, 1995; Moeller et al., 2013), the causative effects of hydration on ecological, behavioral, and physiological parameters of free-ranging animals are virtually unknown. In one of the only field studies manipulating hydration in individual animals, Gila monsters supplemented with water exhibited more surface activity and more fat stored in their tails than control lizards (Davis and DeNardo, 2009). 
Most vertebrates expend a significant amount of energy during reproduction. In viperid snakes, females have been shown to invest over half of their body mass into vitellogenesis (yolk production) and embryo production during the fall and spring prior to summer birthing, (Seigel and Fitch, 1984; Van Dyke and Beaupre, 2011). While numerous studies have focused on the importance of energy in reproduction in females (e.g., Taylor et al., 2005), fewer have considered the role of hydration. Water content of yolk is relatively high in reptiles, with estimates of $>70 \%$ on the first day of incubation in bearded dragons (Packard et al., 1985). Due to the high water content of the yolk, drought may impact a female's ability to reproduce, or it might limit the number or size of offspring she is capable of producing. Additionally, placental lecithotrophic reptiles can compensate for deficits in water or ion content of the yolk via placental provisioning (Stewart et al., 1990). While water deprivation during pregnancy has no effect on litter size or mass in aspic vipers, pregnant females lost $89 \%$ greater mass than nonreproductive females when water-deprived (Dupoué et al., 2015). This suggests that female snakes may compromise their own water balance to benefit their offspring. However, in the event of extreme drought, it may be more beneficial to forego reproduction, or resorb developing follicles, in order to survive to reproduce another year. To date no studies have examined the effects of experimental manipulation of hydration on reproduction in free-ranging reptiles.

During a drought, animals may need to move more frequently and/or for longer distances in search of food. However, exposure to the elements may limit these movements. Spatial ecology may therefore change depending on water availability in the environment. Evaporative water loss increases with movement (Gans et al., 1968), and reptiles that decrease their movements may be doing so in an effort to minimize evaporative water loss. Instead of searching for water during drought, some species are more likely to remain stationary in an effort to conserve energy and water (Duda et al., 1999). Reduced movements as a result of drought may in turn cause reduced mating and foraging opportunities, which have negative fitness consequences. 
Drought results in decreased primary productivity (Zhao and Running, 2010), which can impact rodent populations and therefore the reptile predators that eat them, causing their body condition to decline (Sperry and Weatherhead, 2008). Several aquatic snake species drastically declined in number and appeared to cease reproductive activities during severe drought (Seigel et al., 1995; Willson et al., 2006). These declines were partially attributed to lack of prey, which would cause a decline in body condition of snakes surviving the drought. These studies suggest that prey abundance may mediate the effect of drought on a predator species' body condition. Animals in low body condition or exposed to various other chronic stressors typically exhibit high circulating levels of adrenal glucocorticoids, which among other functions mobilize stored energy by stimulating protein and fat catabolism and gluconeogenesis. Elevated baseline glucocorticoids result in a shift away from unnecessary behaviors and redirect energy toward functions essential for survival, whereas dysfunction in stress reactivity prevents proper response to perturbations (Wingfield et al., 1998). These hormones are often used to quantify stress in vertebrates (Moore et al., 2000; Moore \& Jessop, 2003; Bonier et al., 2009), but no studies have examined whether drought stress affects glucocorticoid levels.

Drought presents an unpredictable and severe environmental stressor. Rattlesnakes are excellent model organisms for physiological studies such as these because they are easy to study in the wild and are highly responsive to changes in the environment (Taylor et al., 2005; Lutterschmidt et al., 2009). Although it is difficult and potentially ethically problematic to experimentally dehydrate snakes in a field setting, it is possible to experimentally hydrate individuals. We conducted a manipulative field experiment to test the hypothesis that hydration positively impacts the spatial ecology, reproduction, and body condition of Northern Pacific rattlesnakes (Crotalus oreganus oreganus). Additionally, we examined whether hydration affects stress hormone levels and the reactivity of the hypothalamic-pituitary-adrenal axis in these snakes. We predicted that experimentally hydrated snakes would be more likely to reproduce, 
exhibit larger home ranges and movements, be in higher body condition, and have reduced glucocorticoid concentrations in comparison to control snakes.

\section{MATERIALS AND METHODS}

\subsection{Study Animals and Site}

Twenty-one adult C. o. oreganus (12 male, 9 female) were captured from Montaña de Oro State Park in Los Osos, San Luis Obispo County, California $\left(35.27^{\circ} \mathrm{N},-120.89^{\circ} \mathrm{W}\right.$, elevation: sea level) between 22 March 2014 and 7 July 2014. Snakes were captured by visual encounter surveys at two sites within the park (Bluff Trail and Sandspit). The sites consist of coastal dune habitat dominated by Black Sage (Salvia mellifera), California Sage (Artemisia californica), invasive Ice Plant (Carpobrotus edulis), Coyote Bush (Baccharis pilularis), and Poison Oak (Toxicodendron diversilobum). Typical annual rainfall in this area is about $43 \mathrm{~cm}$; however, the two years preceding the study each averaged only about $10-15 \mathrm{~cm}$, and less than $5 \mathrm{~cm}$ of precipitation was recorded during the course of the study (source: Morro Bay Fire Station weather station, http://www.ncdc.noaa.gov/). Effects of drought have been long-lasting at this site; many shrubs were dead during a 2016 survey despite a return to average rainfall levels this year (M. Ritter, pers. comm.) Collection and handling of rattlesnakes was carried out under California Department of Fish and Wildlife Scientific Collecting Permit \#SC-12963 and a California State Parks Permit. Use and treatment of snakes was approved by California Polytechnic State University Institutional Animal Care and Use Committee (Protocol \#1403).

Snakes were transported to California Polytechnic State University for radio transmitter implantation. Each snake was housed individually in a 71 by 61 by $30 \mathrm{~cm}$ vision cage (Model V221, LLL Reptile and Supply Company) with a heat pad and hide box (no food or water was provided). Snakes were anesthetized via isoflurane inhalation (Vet One, MWI, USA) and implanted intra-coelomically with a 4-5g SB-2 radio transmitter (Holohil Systems Ltd. Carp, 
Ontario, Canada) and a 3.25g temperature data logger coated in Plastidip (model DS1921G, Maxim Integrated, San Jose, California). Snakes were allowed to recuperate for 1-2 days and then released at their site of capture. Both snout-vent-length (SVL) and mass were recorded at the time of surgery and approximately every three weeks thereafter for each snake.

\subsection{Experimental Manipulation of Hydration}

Snakes were randomly assigned to one of two experimental groups (hydrated and control) with assignments initially balanced between the sexes. Three snakes (two control females, one control male) died during the study; one apparently due to consumption of an excessively large meal, another due to predation, and a third to an infection. The male died midway during the study, so his data were still used for home range analysis. The first group (hydrated treatment, 6 males and 4 females) received an experimental hydration procedure twice per month (see below). The second group (control: 6 males and 3 females) received a sham procedure.

In early April 2014, prior to beginning treatments, blood samples were obtained from each snake via caudal venipuncture (1cc syringe with $25 \mathrm{~g}$ needle) to acquire initial values for blood osmolality. Starting in mid-May, an intragastric tube procedure was used to introduce water into the stomach of each snake in the hydrated group (Davis and DeNardo, 2009). While secured in a plastic restraint tube, a sterilized $52 \mathrm{~cm}$ tomcat urinary catheter rinsed with deionized water was inserted into the snake's mouth and down its esophagus, until the catheter was approximately $1 / 4$ of the way down the snake's body, in the stomach. The snake was then held vertically while a $50 \mathrm{ml}$ syringe with plunger removed was affixed to the exposed end of the catheter. Twenty-five $\mathrm{ml}$ of Millipore water (about 5-15\% of each snake's body mass) was then poured directly into the syringe and allowed to drain into the snake's esophagus and stomach. We used Millipore water to limit any potential effect of dissolved ions present in tap water. Snakes in the control group received the same treatment without the introduction of water 
(sham). After being removed from the snake, the catheter was cleaned with a dry towel to remove any debris from the snake's esophagus that remained on the outside of the catheter. The catheter was then flushed with water and then with ethanol to remove any debris inside the catheter and stored in ethanol until the next treatment. Treatments occurred twice a month with snakes receiving $5.7 \pm 0.5$ (mean \pm 1 SEM) total treatments for an average duration of $3.9 \pm$ 0.2 months. At the end of the study (27 September $2014-2$ November 2014), we again took a blood sample to measure osmolality. All blood samples were transported to the lab within 4 hours and immediately centrifuged. Blood was centrifuged for 3 minutes at 10,000 rpm and plasma was separated and stored at $-2^{\circ} \mathrm{C}$ for $2-3$ days until plasma osmolality was determined with a freezing point depression osmometer (model 3320, Advanced Instruments, Inc., Norwood, Massachusetts).

\subsection{Reproduction}

In August, we used portable ultrasound (Ibex Pro model, E.I. Medical Imaging, Loveland, Colorado, U.S.A.) to examine female snakes for pregnancy in the field. Ultrasound images were acquired using a curved linear transducer at a frequency of $6 \mathrm{MHz}$. When developing fetuses were detected and parturition appeared imminent (e.g., little yolk reserves, Taylor et al., 2005), the snake was brought to the lab and housed individually until parturition in the same cages previously described. If they were in the lab during a designated treatment week, they were given their supplemental water or sham treatment. Females gave birth 2-4 weeks after they were brought to the lab. Within a day after parturition, SVL and mass of the mother and all viable and non-viable offspring were recorded. Non-viable offspring included those offspring that were stillborn or underdeveloped as well as yolk plugs ("slugs"). SVL of the viable neonates was measured with a squeeze-box. Females were released with their neonates at their site of capture within a week of parturition. 


\subsection{Home Range and Activity Patterns}

Snakes were tracked 4-6 times per month for a total average of $18.7 \pm 1.7$ locations per individual throughout the duration of the study for an average of $139 \pm 10$ days. Collectively, snake locations were recorded from 17 May 2014 to 2 November 2014 using a Garmin eTrex Legend H model GPS (Garmin Ltd.). All snake locations were uploaded to the DNRGPS application for Windows (Minnesota Department of Natural Resources) to convert the data to (x, y) coordinates for use in Geographic Information System (GIS) software. ArcMap 9.3 (ESRI, Redlands, California) was used for all spatial analyses. The Home Range Tools extension for ArcGIS (Rodgers et al., 2007) was used to calculate 100\% and $95 \%$ minimum convex polygon (MCP) home range sizes, which are frequently used for studies on rattlesnakes (Putman et. al, 2013). Total distance moved was calculated by measuring the cumulative distance between each consecutive location using the measure tool. The average rate of movement in meters/day was calculated by dividing the total distance moved by the total number of days tracked. These metrics may underestimate actual movement because we did not track snakes every day. However, rattlesnakes are relatively sedentary and these methods provide a rough estimate of movement.

\subsection{Body Condition}

Body condition was calculated by regressing log-transformed body mass and logtransformed SVL and using the residuals as a body condition index (BCl, Cease et al., 2007). Initial and final $\mathrm{BCI}$ were calculated using body mass and SVL measurements taken at the start and end of the study. Because the body condition metric uses mass, we also attempted to control for the water mass added from our experimental water supplementation. We subtracted $25 \mathrm{~g}$ from each individual snake's final mass to obtain a mass representative of the snake without the most recent water supplement. This new mass was then used to calculate a $\mathrm{BCI}$. Because snakes might not be expected to retain the entire $25 \mathrm{~g}$ of water from the most recent 
treatment, we repeated this process by subtracting $20 \mathrm{~g}, 15 \mathrm{~g}, 10 \mathrm{~g}$ and $5 \mathrm{~g}$ from final mass to obtain six different measures of final $\mathrm{BCl}$.

\subsection{Hormones}

At the end of the experiment, we evaluated baseline corticosterone (CORT) levels and stress reactivity of each snake. Snakes were captured and bled via caudal venipuncture for a baseline sample. Time-to-bleed (min) was recorded as well as cloacal temperature $\left({ }^{\circ} \mathrm{C}\right)$. After the first blood sample was collected, snakes were placed into a pillowcase and secured in an opaque plastic bucket for one hour to induce standardized handling stress (Holding et al., 2014). After this time, snakes were bled a second time to obtain stressed hormone levels to test for reactivity of hypothalamic-pituitary-adrenal axis. Samples were kept refrigerated and centrifuged upon return to the lab ( $<4$ hours). Plasma was separated from red blood cells and stored at $2^{\circ} \mathrm{C}$ for 2-3 days and then stored at $-20^{\circ} \mathrm{C}$ until radioimmunoassay. We used radioimmunoassays of CORT to quantify stress reactivity, which is defined as the increase in CORT from baseline following an acute stressor (in this case handling stress) (Holding et al., 2014).

\subsection{Radioimmunoassay}

Radioimmunoassay followed the methods reported in Lind et al. (2010). Plasma samples were sent to Virginia Tech (Blacksburg, VA) for radioimmunoassay. CORT was measured after extraction. When plasma steroid concentrations were predicted to be high, we used $20 \mu$ of plasma (post-stress treatments), and when steroid concentrations were predicted to be low $(<10$ min after capture) we used $50 \mu \mathrm{l}$ of plasma. Samples were equilibrated overnight with 2,000 cpm of tritiated steroid to determine individual extraction efficiency. Extractions were done in 5 $\mathrm{ml}$ of dichloromethane with the organic phase removed and dried in a warm bath under a stream of nitrogen gas, and re-suspended in $10 \%$ ethyl acetate in isooctane. 


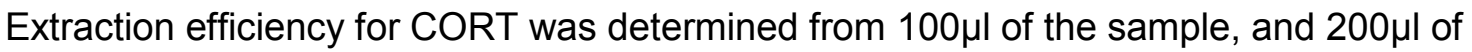
the sample was allocated to each of two duplicates for the assay. Mean recovery for CORT was 78.6\%. Serial dilutions for the standard curve were performed in triplicate (CORT curve range $=$

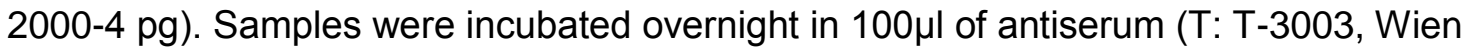

Laboratories, Succasunna, NJ; CORT: Esoterix Endocrinology, Calabasas Hills, CA) and 100 $\mathrm{\mu l}$ of tritiated steroid. Separation of unbound steroid was done using dextran-coated charcoal; bound steroid was then decanted into scintillation vials. A liquid scintillation counter was used to count samples and final concentrations were corrected for extraction efficiency. Intra-assay coefficient of variation (CV) for CORT was $20 \%$.

\subsection{Behaviors}

Each time snakes were tracked, we collected data on visual detectability and body position. Detectability was recorded as whether a snake was visible or not (e.g., not visible underground or in very dense vegetation). Body positions included tight coil, moderate coil, loose coil, and elongated. Snakes were considered to be in a tight coil when greater than $25 \%$ of its body was under coils, while a moderate coil was less than $25 \%$ coverage. A loose coil occurred when all of the snake's body was visible, but the snake was still in a coiled position. Elongated snakes included any snake that could not be considered coiled. We also noted whether or not snakes had recently fed by observation of a noticeable food bulge during tracking or palpation when snakes were captured. We also recorded whether they rattled, fled, or tongue-flicked upon approach; however, these behaviors were so rare that quantitative analysis was not possible.

\subsection{Statistical Analysis}


All statistical tests were performed in Minitab 16 (Minitab Inc. 2010) or JMP (SAS Institute Inc. 2013). All variables were subject to tests of normality and for homogeneity of variances. When these assumptions were violated, transformations were applied.

We considered a variety of independent variables for our statistical analysis that included treatment group, sex, time, and their interactions. Our dependent variables included measures of plasma osmolality, reproduction, home range and movement parameters, body condition, and hormone concentrations. We also considered possible covariates such as SVL, mass, number of GPS locations, body condition, cloacal body temperature, time-to-bleed, and plasma osmolality. We removed non-significant factors and covariates; final models are reported in the Results.

The effect of treatment on plasma osmolality was evaluated using a generalized linear model with treatment as the factor. The effects of hydration treatment and sex on plasma osmolality were modeled using ANOVA; however, sex was consistently non-significant and not included in the final model. Home range sizes measured using $100 \%$ and $95 \%$ MCPs were analyzed as an ANCOVA with SVL as a covariate. Treatment group, sex, and the interaction between treatment and sex were included in the model. Total distance moved and distances moved per day were analyzed in the same way. We used a repeated measures ANOVA to examine the effects of treatment, time (initial or end of study), and the interaction between the treatment and time on $\mathrm{BCI}$. Snake ID was included as a random factor. We performed this analysis for unadjusted $\mathrm{BCl}$ and for each of the $\mathrm{BCl}$ adjusted for possible added water mass. We did not include pregnant females in this analysis as their $\mathrm{BCls}$ would be inflated by the fetuses. The effect of treatment group, sample (baseline or stressed) and the interaction between treatment and sample on CORT was modeled with an ANCOVA with cloacal body temperature, initial body condition, and plasma osmolality as covariates. Due to CORT's complex interactions with many life-history traits, we also used linear regression to examine potential relationships with home range and activity patterns, osmolality, and thermal biology. 
We used ANOVA to determine if treatment group or sex had an effect on the number of observations in which snakes were visible or the amount of time spent in a particular body position. The arcsine-square root transformation improved the normality of both variables; however, only frequency of time spent above or below ground was transformed sufficiently to fit the normal distribution.

\section{RESULTS}

\subsection{Osmolality}

Plasma osmolality was significantly lower in hydrated snakes (mean $=261.7 \pm 7.7$ $\mathrm{mOsm} / \mathrm{kg}$ ) than in control snakes (mean $=306.8 \pm 6.3 \mathrm{mOsm} / \mathrm{kg})$ at the end of the study $\left(\mathrm{F}_{1,14}=\right.$ $16.74, p=0.002)$. Neither mass nor the number of treatments co-varied with plasma osmolality, and therefore were not included in the final model.

\subsection{Reproduction}

Comparison of the frequency of reproductive females in each treatment group was unnecessary because all four hydrated females gave birth during the study while no control females gave birth. All reproductive females gave birth to at least one viable offspring and one unviable offspring (e.g. stillborn, underdeveloped, or a yolk plug). Specifically, each of the four females had a single stillborn and a single yolk plug along with either one, two, three, or four viable neonates.

\subsection{Movements and Home Range}

Hydration had no effect on total distance moved $\left(F_{1,14}=0.60, p=0.45\right)$, nor did it interact with sex to affect movement $\left(F_{1,14}=1.23, p=0.27\right)$. Males moved a larger total distance than females (ANCOVA: $F_{1,14}=8.87, p=0.01$, Fig. 1$)$, and SVL was a significant covariate $\left(F_{1,14}=\right.$ 
23.69, $p<0.001$ ), again with larger snakes moving farther. Distance moved per day was not affected by treatment group or sex or their interaction (treatment group: $F_{1,14}=0.05, p=0.83$; sex: $F_{1,14}=1.22, p=0.29$; treatment group by sex: $\left.F_{1,14}=2.95, p=0.11\right)$. SVL co-varied with distance moved per day, with larger snakes moving longer distances $\left(F_{1,14}=8.10, p=0.013\right)$. One female moved an unusually large total distance (1572 m), which substantially increased the mean total distance moved for females (overall mean $=408 \mathrm{~m}$; mean with outlier female removed $=214 \mathrm{~m})$. However, removal of this individual from the analyses of total distance moved and distance moved per day did not affect the results.

Home range size was not significantly affected by treatment group (ANCOVA: 100\% MCP: $F_{1,14}=0.98, p=0.339 ; 95 \%$ MCP: $\left.F_{1,14}=0.42, p=0.527\right)$. Males had larger $100 \%$ MCP home ranges than females $\left(F_{1,14}=4.65, p=0.049\right)$, but not 95\% MCP home ranges $\left(F_{1,14}=\right.$ $3.40, p=0.086)$; and the interaction between treatment and sex was not significant $(100 \%$ MCP: $F_{1,14}=1.08, p=0.316 ; 95 \%$ MCP: $\left.F_{1,14}=0.92, p=0.355 ; F i g, 2\right)$. SVL was a significant covariate for both 100\% MCP $\left(F_{1,14}=16.61, p=0.002\right)$ and $95 \% \operatorname{MCP}\left(F_{1,14}=11.19, p=0.005\right)$, with larger snakes having larger home range sizes. Two snakes ( 1 male, 1 female) had relatively large home ranges and appeared to exert high leverage, thus a separate analysis was performed that excluded these individuals. The removal of these two snakes caused the difference in home range size between the sexes to disappear (100\% MCP: $F_{1,12}=1.55, p=$ $0.237 ; 95 \%$ MCP: $F_{1,12}=0.73, p=0.409$ ).

\subsection{Body Condition}

The repeated measures ANOVA indicated a significant effect of treatment group $\left(F_{1,22}=\right.$ $6.96, p=0.015$ ), with hydrated snakes having significantly higher $\mathrm{BCl}$ than control snakes at the end of the study $(t=-3.10, p=0.009)$ but not at the beginning $(t=-2.45, p=0.25)$. There was a trend for an interaction between the treatment group and time (initial or end of study) ( $F_{1,22}=$ 3.72, $p=0.067$, Fig. 3). Adjusting final $\mathrm{BCl}$ by subtracting $25 \mathrm{~g}$ of water provided similar results, 
with the overall model showing hydrated $\mathrm{BCl}$ higher than control $\mathrm{BCl}\left(\mathrm{F}_{1,22}=4.70, \mathrm{p}=0.041\right)$, a non-significant interaction between treatment group and time $\left(F_{1,25}=2.12, p=0.160\right)$, and final $\mathrm{BCl}$ higher in hydrated snakes than in control snakes $(t=-2.45, \mathrm{p}=0.03)$. Sex was consistently non-significant so it was not included in the model.

\subsection{Corticosterone}

Stressed CORT concentrations were significantly higher than baseline concentrations $\left(F_{1,9.8}=263.69, p<0.001\right.$, Fig. 4). However, there was no effect of sex or hydration treatment on any aspect of CORT physiology. Initial $\mathrm{BCl}$ was significant as a covariate, with higher $\mathrm{BCl}$ corresponding to lower CORT concentrations $\left(F_{1,5.82}=17.83, p=0.006\right)$. Osmolality was also a significant covariate, with higher osmolalities corresponding to higher CORT concentrations $\left(F_{1,5.81}=11.17, p=0.016\right)$. Finally, cloacal body temperature was also a significant covariate, with higher temperatures corresponding to higher CORT $\left(F_{1,6.1}=8.77, p=0.025\right)$.

\subsection{Behavior}

There were no significant differences between hydrated and control snakes or between the sexes in frequency above or below ground, or frequency found in a particular body position (Table 1). All snakes spent significantly more time in a moderate coil than any other body position (ANOVA: $F_{3,75}=27.08, p<0.001$ ). Snakes spent a significantly larger portion of time above ground than below ground $\left(F_{1,37}=73.62, P<0.001\right)$.

\section{DISCUSSION}

This study is the first to manipulate hydration in free-ranging snakes. We hypothesized that hydration would positively impact physiology and behavior of rattlesnakes and our predictions for reproduction and body condition were supported. Plasma osmolality of hydrated 
snakes was significantly lower than control snakes at the end of the study, as expected. Snakes receiving supplemental hydration did absorb the water into circulation, showing that our hydration procedure worked. Although it is not possible to rule out the notion that our control snakes were not functionally dehydrated but that the hydrated snakes were "overhydrated," our results potentially suggest the possibility that hydrated female snakes used the added water for reproduction. We observed a clear relationship between supplemental hydration and the production of a litter by female snakes. We saw no effect of hydration on movement patterns; however, we did see an increase in $\mathrm{BCl}$ of hydrated snakes at the end of the study. Finally, we did not see any differences in baseline CORT or stress reactivity between hydrated and control groups, but initial $\mathrm{BCI}$ was a significant covariate with CORT concentration, with higher initial $\mathrm{BCl}$ corresponding to lower CORT. This suggests that $\mathrm{BCl}$ at the beginning of the active season may determine how a snake responds physiologically at the end of the active season, depending on energy intake.

Our prediction that a larger proportion of hydrated females would give birth was supported, as all four hydrated females gave birth to a litter while no control females produced offspring. Although we randomly assigned snakes to treatment groups, the small sample size of females in this study limits our ability to conclude that the observed difference between groups is not due to chance. Most species of female rattlesnakes begin vitellogenesis in the fall or early spring, several months before the time when we began supplementally hydrating snakes. So, if indeed the effect was due to our supplemental hydration, one possible mechanism is that some of the control snakes resorbed their follicles due to a deficit in water, whereas hydrated snakes were able to continue developing follicles. In one of the few experimental studies on freeranging female rattlesnakes, supplemental feeding significantly increased the incidence of pregnancy in a population of free-ranging Western diamond-backed rattlesnakes in Arizona (Taylor et al., 2005). Hydration should be very important for reproduction too, but long-term supplemental hydration experiments are needed to understand how water affects reproduction. 
Water comprises a large proportion of yolk, with estimates as high as $80 \%$ in oviparous reptiles (Packard et al., 1985). In viviparous reptiles, water content rises dramatically from $40-50 \%$ in oviductal eggs to $70-80 \%$ in neonates (Stewart and Castillo, 1984). Some female reptiles can decrease their clutch sizes via resorption of eggs or follicles (Sinervo and Licht, 1991; Bonnet et al., 2008), and if conditions are poor they might do this to conserve water. Most rattlesnakes reproduce at most every other year (Fitch, 1949) and are described as capital breeders, relying for the most part on stored energy for reproduction (Diller and Wallace, 1984). It is unlikely that the energy available during a summer when a female is pregnant limits reproduction in rattlesnakes because of their reliance on stored energy. Rather, the previous year's energy intake is primarily used for the production of offspring. Water availability, however, has the potential to directly influence reproduction in the current year because rattlesnakes do not store water in an accessory organ like a bladder. Any water allocated toward yolk production or the resultant offspring must come from the female's tissues, which may result in a dramatic increase in plasma osmolality and severe dehydration. If supplemental hydration increases reproductive frequency in the long-term, then our results suggest the possibility that dehydration physiologically limits reproduction in rattlesnakes.

The average clutch size in this study is smaller than those reported for other members of the western rattlesnake complex (Crotalus oreganus spp.). Fitch (1949) reported an average clutch size of 9.9 in the Sierra Nevada where females ranged from $300-400 \mathrm{~g}$. A study in Idaho reported an average clutch size of 5.5, with reproducing females averaging $192 \mathrm{~g}$ in mass (Diller and Wallace, 1984). Snakes in our study had an average clutch size of two live neonates (range $1-4$ ) and average body mass of $210 \mathrm{~g}$. It is possible that the small clutch size is the result of the accumulated effects of dehydration from previous years, analogous to reductions in clutch size observed in striped plateau lizards during drought (Abell, 1999).

We predicted that hydrated snakes would make larger movements and have larger home ranges, yet there were no differences in movement parameters between hydrated and 
control snakes, indicating that hydration does not affect spatial ecology in rattlesnakes, at least within the hydration levels and time frame investigated in this study. There are several potential explanations for the lack of effect of hydration on movement. Low sample size and high individual variation in movement variables may have limited our ability to detect an effect of hydration. Although the mean home range size for hydrated males was twice that of control males, this was not significant due to high variation among individuals. Male rattlesnakes typically show dramatic individual variation in home range size (Putman et al., 2013), and with a larger sample we may have detected a difference between hydrated and control snakes. As this was a short-term study, movement and home range sizes may be underestimated compared to annual values. Indeed, home ranges at this site were relatively small compared to other published home range data for the C. oreganus complex (Putman et al., 2013; Holding et al., 2014). Our study site is bounded on one side by the ocean, which may partially explain the small home ranges. Sparse vegetation and open habitats may also limit movement because predators are more apt to see potential prey. Also, as sit-and-wait foragers that feed infrequently (Klauber, 1956), rattlesnakes have a low-energy lifestyle that may allow for movement even during times of drought. Many rattlesnake species diverged in the warm deserts of North America (Douglas et al., 2006) and currently occupy much of the American Southwest (Klauber, 1956), a testament to their adaptability and tolerance for dry climates. Finally, we found that, like most species of rattlesnakes, female $C$. o. oreganus have smaller home ranges than males (Putman et al., 2013). This is likely because males make long-distance movements in search of mates.

Regarding the effect of hydration on body condition, our prediction that final $\mathrm{BCl}$ of hydrated snakes would be higher than that of control snakes was supported as hydrated snakes had significantly higher body condition than control snakes at the end of the study but not at the beginning, even after adjusting for potential added water weight. Our water supplement may have provided some benefit to the hydrated group of snakes. One possibility is that hydration 
allowed them better hunting success. During the study only six snakes were observed with food bulges, but other successful predation events likely went unobserved. We did not detect a difference between groups in amount of time spent on the surface, but hydrated snakes may have nonetheless obtained more prey. Without detailed data on the reason for the mass gain in hydrated snakes, we can only speculate on this result.

Our prediction that CORT would be higher in control snakes was not supported. The only significant difference was between baseline and stressed samples, with no interaction with treatment group, indicating that baseline CORT and stress reactivity were not affected by hydration. Previous studies have shown that water deprivation stimulates elevated CORT in mice (Roberts et al., 2011). Since rattlesnakes are adapted to arid environments, it is possible that they may require more severe environmental stress to trigger sustained release of CORT. Bradshaw and Rice (1981) found a similar result in Gould's monitor lizards (Varanus gouldii), where differences in hydration were unrelated to CORT. However, it is interesting to note that in our study, initial body condition and CORT concentration were significantly and negatively correlated, meaning that fatter snakes had lower CORT. This relationship is well supported in the literature (Romero and Wikelski, 2001), as CORT tends to be released when animals are in negative energy balance because it mobilizes stored energy for use by the body. In terms of CORT as an indicator of stress levels, the lack of a difference in CORT concentration at the end of the study suggests that control snakes were not more stressed than hydrated snakes. As stated earlier, it is possible that the control snakes were not in fact dehydrated in a physiologically meaningful way, given that rattlesnakes are adapted to arid environments, but that the hydrated group was actually hydrated beyond normal levels. However, considering the positive association between plasma osmolality and CORT, hydration state is potentially related to the stress levels of individuals in our study. Given that glucocorticoids can interact with hydration in ways unrelated to stress per se, including inhibition of vasopressin release from the neurohypophysis (Raff, 1987) and strong binding affinity with mineralocorticoid receptors (Lan et 
al., 1982), further study on the relationships between plasma osmolality and CORT levels would be valuable.

Finally, we found that tongue-flicking and rattling rates were no different between sexes or treatment groups and were overall exceptionally rare. Klauber (1956) wrote that a rattlesnake's initial response to an intruder is remaining stationary to avoid detection. Only after the snake has surely been seen does it respond, usually first with an attempt to flee, followed by rattling and subsequent striking if necessary. Studies examining snake-human interactions have found that rattlesnakes typically do not respond to approaches by humans, and also that repeated handling does not increase the frequency of defensive behaviors (Prior and Weatherhead, 1994; Holding et al., 2014). Snakes were detected on the surface nearly $80 \%$ of the time, with no significant differences between treatment groups or sexes. The large proportion of time spent coiled on the surface reflects their ambush-style foraging and relative inactivity above ground suggesting that hydration does not influence these behaviors in snakes. Two separate studies report rattlesnakes to be surface active approximately $50 \%$ of the time (Beck, 1995; Davis et al., 2008). Considering we did not track these snakes year-round, our estimate of $80 \%$ would most likely diminish if snakes were tracked during winter months when snakes are less active. Although our handling of the snakes in both groups every two weeks may have caused them to behave differently, rattlesnakes appear to be robust to frequent handling (Holding et al., 2014). Our results differ from those of Davis and DeNardo (2009), who found that supplemental hydration led to increased surface activity of Gila Monsters. Active foraging Gila Monsters are subjected to more extreme conditions than our rattlesnakes in terms of temperature and dryness, making water more of a limiting resource for them.

This study is one of the first experimental projects on hydration in free-ranging reptiles, and it thereby adds key conclusions to the strong literature showing that hydration can have dramatic effects on the ecology, physiology, and behavior of reptiles (Nagy, 1972; Turner et al., 1986; Henen et al., 1998; Henen, 2002; Davis and DeNardo, 2009; Winne et al., 2010). Our 
data suggest that supplemental hydration affects reproduction and body condition of $C .0$. oreganus, while spatial ecology and stress hormone concentrations are unrelated. The positive effect of hydration on female reproduction is striking and deserves further study to provide mechanistic support to the hypothesis that hydration is a limiting factor for reproduction in snakes. Furthermore, it would be interesting to examine whether hydration affects male reproductive success, for example by affecting mate-searching or courtship, perhaps by analyzing paternity of neonate snakes. The effect of hydration on spatial ecology of populations with larger home ranges and greater drought stress, for example desert species, would also be informative. Hydration influenced body condition in our study, but the mechanism by which it did so is unclear. Finally, the fact that supplemental hydration did not influence baseline CORT or stress reactivity supports the idea that rattlesnakes are adapted to arid environments such that varying hydration states do not impact stress hormone levels. Future studies should focus on the physiological mechanisms that allow rattlesnakes to cope with prolonged dry conditions.

\section{ACKNOWLEDGMENTS}

This work was funded by California Polytechnic State University Biological Sciences Department and California State Parks. Mike DeLea, Alex Harrison, Matt Kane, Gillian Larson, Nikki Murphey, Abby Nemeth, Greg Reading, Liz Saldo, TJ Traber, Kate Vanderslice, Jeff Warshauer, and Scott Wong assisted with fieldwork. Tony Frazier provided valuable advice and assistance during all stages of this work. Natalie Claunch provided field assistance as well as comments on this manuscript. Funding was provided by the Cal Poly Biological Sciences Department and a U.S. National Science Foundation (NSF) grant IOS-1145625 to ITM.

\section{LITERATURE CITED}

Abell, A.J., 1999. Variation in clutch size and offspring size relative to environmental conditions in the lizard Sceloporus virgatus. Journal of Herpetology 33, 173-180. 
Beck, D.D., 1995. Ecology and energetics of three sympatric rattlesnake species in the Sonoran Desert. Journal of Herpetology 29, 211-223.

Bonier, F., Martin, P.R., Moore, I.T., Wingfield, J.C., 2009. Do baseline glucocorticoids predict fitness? Trends in Ecology and Evolution 24, 634-642.

Bonnet, X., Akoka, S., Shine, R., Pourcelot, L., 2008. Disappearance of eggs during gestation in a viviparous snake (Vipera aspis) detected using non-invasive techniques. Acta Herpetologica 3, 129-137.

Bradshaw, S.D., Rice, G.E., 1981. The effects of pituitary and adrenal hormones on renal and postrenal reabsorption of water and electrolytes in the lizard, Varanus gouldii (Gray). General and Comparative Endocrinology 44, 82-93.

Cease, A.J., Lutterschmidt, D.I., Mason, R.T., 2007. Corticosterone and the transition from courtship behavior to dispersal in male red-sided garter snakes (Thamnophis sirtalis parietalis). General and Comparative Endocrinology 150, 124-131.

Churchill, T.A., Storey, K.B., 1995. Metabolic effects of dehydration on an aquatic frog, Rana pipiens. The Journal of Experimental Biology 198, 147-154.

Davis, J., DeNardo, D., 2009. Water supplementation affects the behavioral and physiological ecology of Gila monsters (Heloderma suspectum) in the Sonoran Desert. Physiological and Biochemical Zoology 82, 739-48.

Davis, J.R., Taylor, E.N., DeNardo, D.F., 2008. An automated temperature-based option for estimating surface activity and refuge use patterns in free-ranging animals. Journal of Arid Environments. 72, 1414-1422.

Diller, L., Wallace, R., 1984. Reproductive biology of the northern Pacific rattlesnake (Crotalus viridis oreganus) in northern Idaho. Herpetologica 40, 182-193.

Douglas, M.E., Douglas, M.R., Schuett, G.W., Porras, L.W., 2006. Evolution of rattlesnakes (Viperidae; Crotalus) in the warm deserts of western North America shaped by 
Neogene vicariance and Quaternary climate change. Molecular Ecology 15, 33533374.

Duda, J.J., Krzysik, A.J., Freilich, J.E., 1999. Effects of drought on desert tortoise movement and activity. The Journal of Wildlife Management 63, 1181-1192.

Dupoué, A., Brischoux, F., Angelier, F., DeNardo, D.F., Wright, C.D., Lourdais, O., 2015. Intergenerational trade-off for water may induce a mother-offspring conflict in favour of embryos in a viviparous snake. Functional Ecology 29, 414-422.

Fitch, H.S., 1949. Study of snake populations in central California. American Midland Naturalist 41, 513-579.

Gans, C., Krakauer, T., Paganelli, C.V., 1968. Water loss in snakes: interspecific and intraspecific variability. Comparative Biochemistry and Physiology 27, 747-761.

Henen, B.T., 2002. Reproductive effort and reproductive nutrition of female desert tortoises: essential field methods. Integrative and Comparative Biology 42, 43-50.

Henen, B.T., Peterson, C.C., Wallis, I.R., Berry, K.H., Nagy, K.A., 1998. Effects of climatic variation on field metabolism and water relations of desert tortoises. Oecologia 117, $365-373$.

Holding, M.L, Frazier, J.A., Dorr, S.W., Henningsen, S.N., Moore, I.T., Taylor, E.N., 2014. Physiological and behavioral effects of repeated handling and short-distance translocations on free-ranging Northern Pacific rattlesnakes (Crotalus oreganus). Journal of Herpetology 48, 233-239.

Klauber, L.M., 1956. Rattlesnakes: Their Habits, Life History and Influence on Mankind. University of California Press, Berkeley.

Lan, N.C., Graham, B., Bartter, F.C., Baxter, J.D., 1982. Binding of steroids to mineralocorticoid receptors: implications for in vivo occupancy by glucocorticoids. The Journal of Clinical Endocrinology \& Metabolism 54, 332-342. 
Lillywhite, H.B., Babonis, L.S., Sheehy, C.M., Tu, M., 2008. Sea snakes (Laticauda spp.) require fresh drinking water: implication for the distribution and persistence of populations. Physiological and Biochemical Zoology 81, 785-796.

Lind, C.M., Husak, J.F., Eikenaar, C., Moore, I.T., Taylor, E.N., 2010. The relationship between plasma steroid hormone concentrations and the reproductive cycle in the northern Pacific rattlesnake, Crotalus oreganus. General and Comparative Endocrinology 166, 590-599.

Lutterschmidt, W.I., Lutterschmidt, D.I., Mason, R.T., Reinert, H.K., 2009. Seasonal variation in hormonal responses of timber rattlesnakes (Crotalus horridus) to reproductive and environmental stressors. Journal of Comparative Physiology B $179,747-57$.

Moeller, K.T., Butler, M.W., DeNardo, D.F., 2013. The effect of hydration state and energy balance on innate immunity of a desert reptile. Frontiers in Zoology 10, 1-10.

Moore, I.T., Lerner, J.P., Lerner, D.T., Mason, R.T., 2000. Relationships between annual cycles of testosterone, corticosterone, and body condition in male red-spotted garter snakes, Thamnophis sirtalis concinnus. Physiological and Biochemical Zoology 73, 307-312.

Moore, I.T., Jessop, T.S., 2003. Stress, reproduction, and adrenocortical modulation in amphibians and reptiles. Hormones and Behavior 43, 39-47.

Nagy, K.A., 1972. Water and electrolyte budgets of a free-living desert lizard, Sauromalus obesus. Journal of Comparative Physiology 79, 39-62.

Packard, M. J., Packard, G.C., Miller, J.D., Jones, M.E., Gutzke, W.H.N., 1985. Calcium mobilization, water balance, and growth in embryos of the agamid lizard Amphibolurus barbatus. Journal of Experimental Zoology 235, 349-357.

Prior, K.A., Weatherhead, P.J., 1994. Response of free-ranging Eastern massasauga rattlesnakes to human disturbance. Journal of Herpetology 28, 255-257. 
Putman, B.J., Lind, C., Taylor, E.N., 2013. Does size matter? Factors influencing the spatial ecology of northern Pacific rattlesnakes (Crotalus oreganus oreganus) in central California. Copeia 2013, 485-492.

Raff, H., 1987. Glucocorticoid inhibition of neurohypophysial vasopressin secretion. American Journal of Physiology - Regulatory, Integrative, and Comparative Physiology 252, R635-R644.

Roberts, E.M., Pope, G.R., Newson, M.J.F., Lolait, S.J., O'Carroll, A.M., 2011. The vasopressin $\mathrm{V} 1 \mathrm{~b}$ receptor modulates plasma corticosterone responses to dehydration-induced stress. Journal of Neuroendocrinology 23, 12-19.

Rodgers, A.R., Carr, A.P., Beyer, H.L., Smith, L., Kie, J.G., 2007. HRT: Home range tools for ArcGIS.

Romero, L., Wikelski, M., 2001. Corticosterone levels predict survival probabilities of Galapagos marine iguanas during El Nino events. Proceedings of the National Academy of Sciences of the United States of America 98, 7366-7370.

Seigel, R.A., Fitch, H.S., 1984. Ecological patterns of relative clutch mass in snakes. Oecologia 61, 293-301.

Seigel, R.A., Gibbons, J.W., Lynch, T.K., 1995. Temporal changes in reptile populations: effects of a severe drought on aquatic snakes. Herpetologica 51, 424-434.

Shoemaker, V. II, Nagy, K.A., 1977. Osmoregulation in amphibians and reptiles. Annual Review of Physiology 39, 449-471.

Sinervo, B., Licht, P., 1991. Hormonal and physiological control of clutch size, egg size, and egg shape in side-blotched lizards (Uta stansburiana) - Constraints on the evolution of lizard life histories. Journal of Experimental Zoology 257, 252-264.

Sperry, J.H., Weatherhead, P.J., 2008. Prey-mediated effects of drought on condition and survival of a terrestrial snake. Ecology 89, 2770-2776. 
Stewart, J.R., Blackburn, D.G., Baxter, D.C., Hoffman, L.H., 1990. Nutritional provision to embryos in a predominantly lecithotrophic placental reptile, Thamnophis ordinoides (Squamata: Serpentes). Physiological Zoology 63, 722-734.

Stewart, J., Castillo, R., 1984. Nutritional provision of the yolk of two species of viviparous reptiles. Physiological Zoology 57, 377-383.

Taylor, E.N., Malawy, M.A., Browning, D.M., Lemar, S.V., DeNardo, D.F., 2005. Effects of food supplementation on the physiological ecology of female western diamondbacked rattlesnakes (Crotalus atrox). Oecologia 144, 206-213.

Trenberth, K.E., Dai, A., van der Schrier, G., Jones, P.D., Barichivich, J., Briffa, K.R., Sheffield, J., 2014. Global warming and changes in drought. Nature Climate Change 4, 7-22.

Turner, F.B., Hayden, P., Burge, B.L., Roberson, J.B., 1986. Egg production by the desert tortoise (Gopherus agassizii) in California. Herpetologica 42, 93-104.

Van Dyke, J.U., Beaupre, S.J., 2011. Bioenergetic components of reproductive effort in viviparous snakes: costs of vitellogenesis exceed costs of pregnancy. Comparative Biochemistry and Physiology - Part A 160, 504-515.

Willson, J.D., Winne, C.T., Dorcas, M.E., Gibbons, J.W., 2006. Post-drought responses of semi-aquatic snakes inhabiting an isolated wetland: Insights on different strategies for persistence in a dynamic habitat. Wetlands 26, 1071-1078.

Wingfield, J.C., Maney, D.L., Breuner, C.W., Jacobs, J.D., Ramenofsky, M., Richardson, R.D., 1998. Ecological bases of hormone-behavior interactions: the "emergency life history stage." American Zoologist 38, 191-206.

Winne, C.T., Willson, J.D., Gibbons, J.W., 2010. Drought survival and reproduction impose contrasting selection pressures on maximum body size and sexual size dimorphism in a snake, Seminatrix pygaea. Oecologia 162, 913-922. 
Zhao, M., Running, S.W., 2010. Drought-induced reduction in global terrestrial net primary production from 2000 through 2009. Science 329, 940-943. 
Table 1. Mean frequency \pm 1 SEM of time spent in a particular body position and of time spent above or below ground of Northern Pacific rattlesnakes (Crotalus o. oreganus).

\begin{tabular}{cccc} 
Coil & \multicolumn{3}{c}{ Location } \\
\hline \multirow{2}{*}{ Tight } & Frequency & & Frequency \\
\cline { 2 - 2 } Moderate & $0.18 \pm 0.03$ & & \\
Loose & $0.54 \pm 0.04$ & Above & $0.79 \pm 0.04$ \\
Elongate & $0.18 \pm 0.03$ & Below & $0.21 \pm 0.04$ \\
& $0.10 \pm 0.02$ & &
\end{tabular}


Figure 1. Male Crotalus o. oreganus moved a larger total distance than females, regardless of hydration treatment. Males moved $257 \mathrm{~m}$ more than females on average. The large variance in the control females is due to a single outlier female, whose removal from the model did not influence the outcome. Sample sizes are represented above bars and error bars are 1 SEM.

Figure 2. Male Crotalus o. oreganus had larger 100\% and 95\% Minimum Convex Polygon (MCP) home range areas than females regardless of treatment group. Sample sizes are shown above bars, and error bars are 1 SEM.

Figure 3. Body condition index $(\mathrm{BCl})$ for Crotalus 0 . oreganus was higher at the end of the study period in hydrated snakes than control snakes even after adjusting for up to 25 grams of weight added by the most recent water treatment.

Figure 4. Corticosterone (CORT) concentrations of Crotalus o. oreganus were not significantly different between treatment groups or sexes. Stressed CORT concentration was consistently higher than baseline CORT regardless of treatment group or sex. There were no effects of hydration or sex on CORT physiology. Error bars are 1 SEM. 


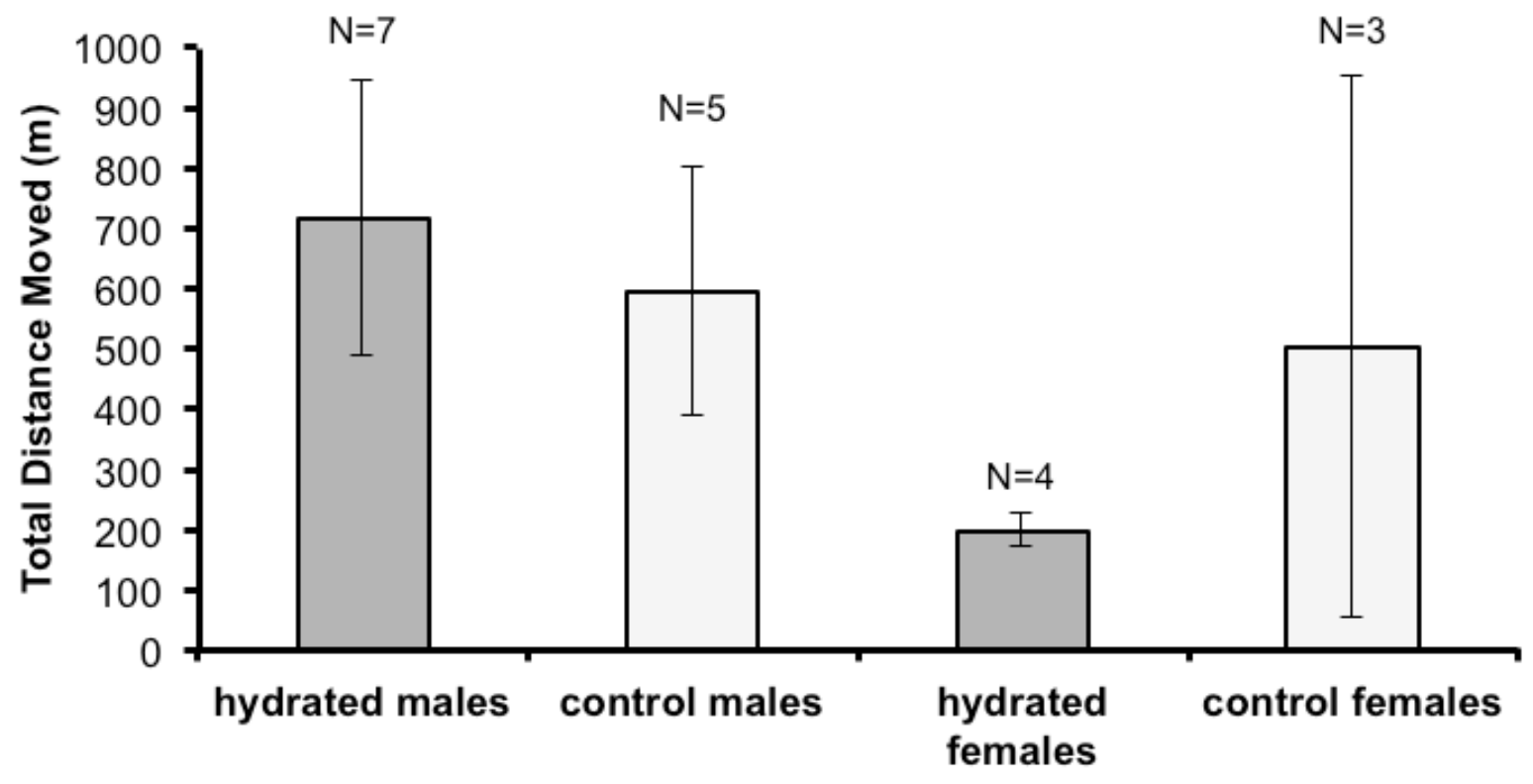




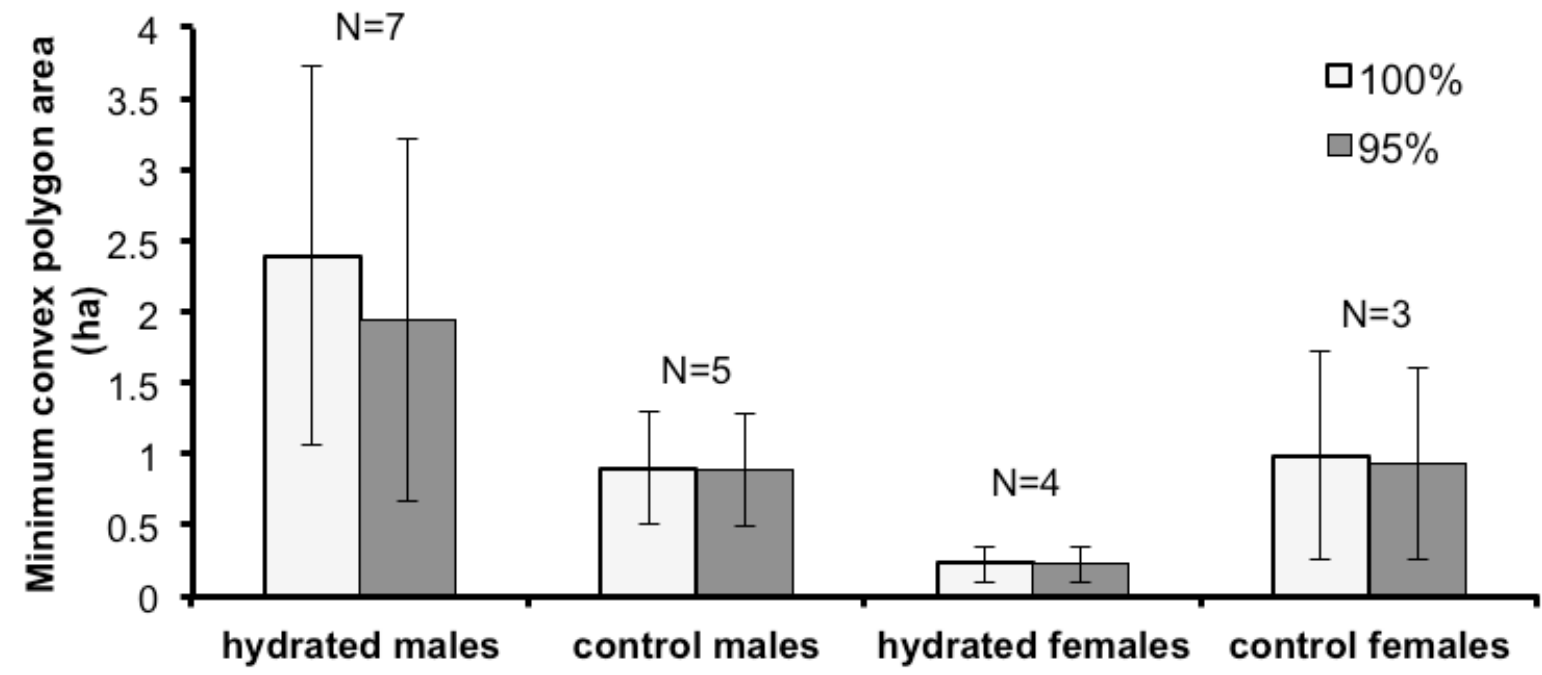




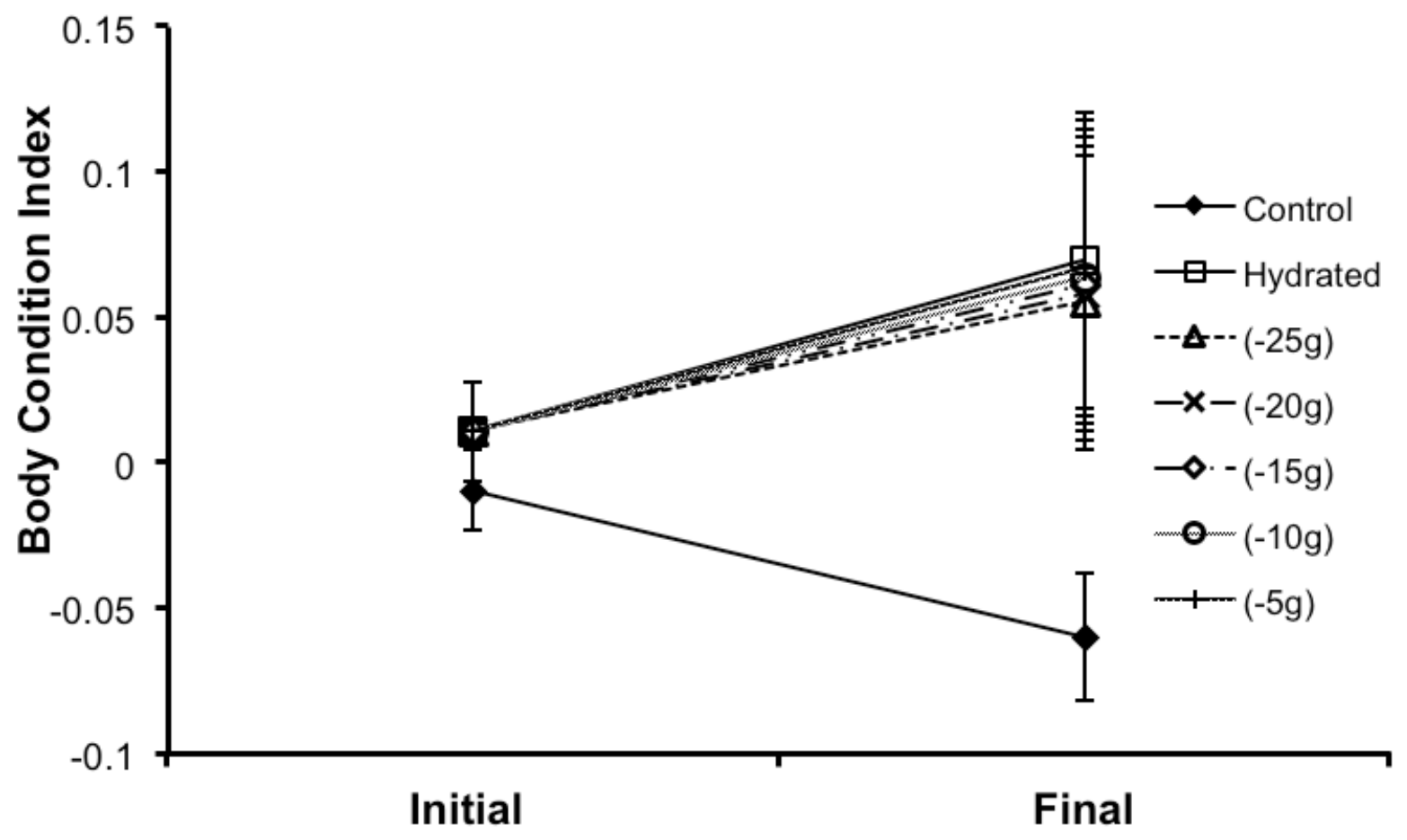




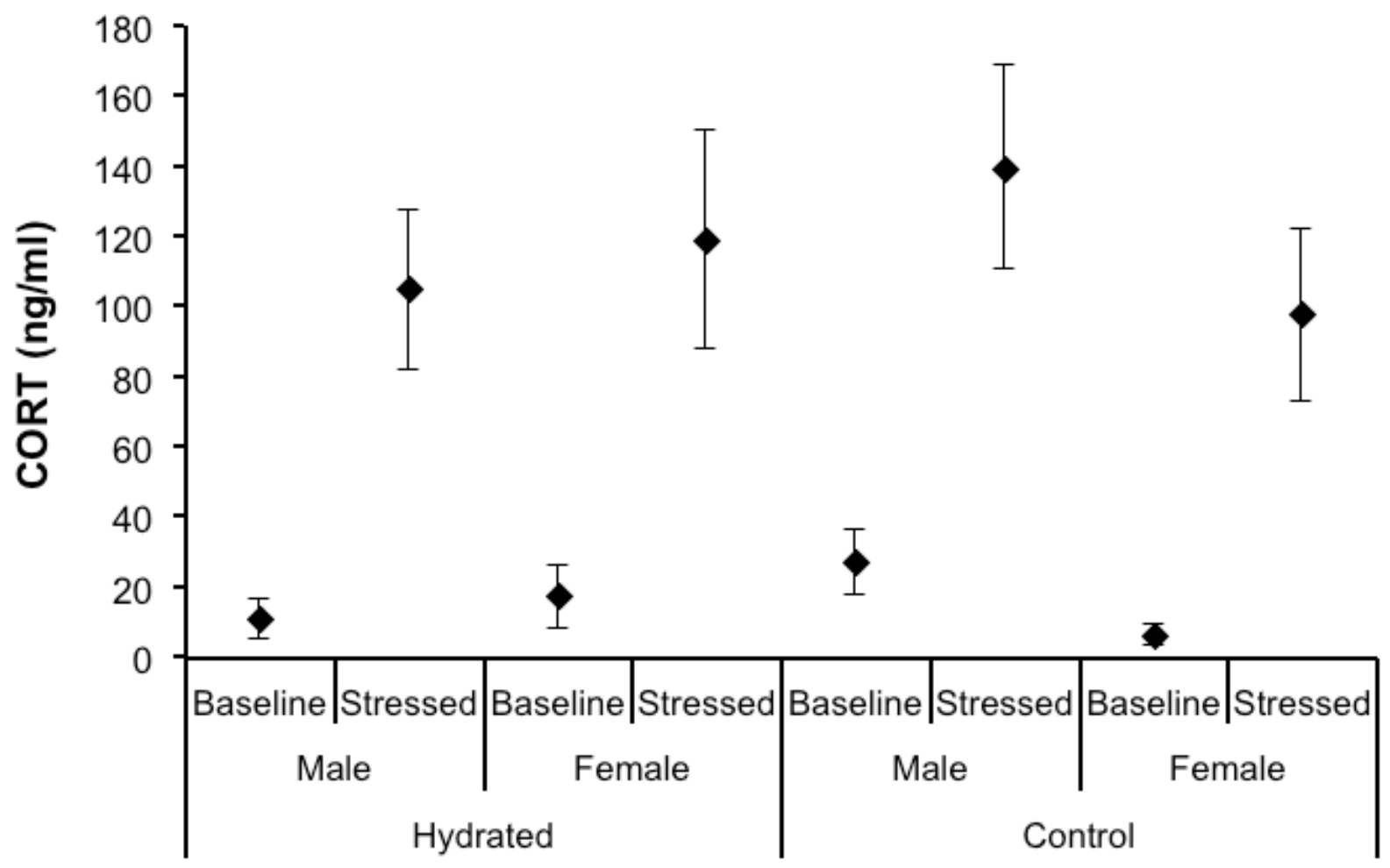

